\title{
The Egg-Yolk Reaction of Aerobic Sporing Bacilli
}

\author{
By C. A. McGaUgheY and H. P. CHU \\ Institute of Animal Pathology, University of Cambridge
}

\begin{abstract}
SUMMARY : Among a large number of strains of aerobic sporing bacilli only Bacillus cereus, $B$. mycoides and, to a lesser extent, $B$. anthracis were able to produce turbidity and formation of a curd in saline extract of egg-yolk. None of the other species tested, namely, B. alvei, B. alcalophilus, B. brevis, B. carotarum, B. circulans, B. coagulans, B. fusiformis, B. licheniformis, B. macerans, B. megatherium, B. pumilus, $B$. polymyxa, B. orpheus, B. repens and $B$. subtilis caused any opalescence in the yolk medium. The yolk reaction was due to the action of phospholipinase produced by the organisms. As in the case of $\mathrm{Cl}$. welchii $\alpha$-toxin, the yolk curd-forming activity of $B$. cereus and $B$. mycoides also was associated with haemolytic activity. The substances responsible for these activities appear to be similar, and may be identical. The yolk reaction has proved useful for the rapid identification of $B$. cereus, as it is more specific than any of the other distinguishing tests hitherto employed. The three positive organisms, B. cereus, B. mycoides and $B$. anthracis, have been considered by previous workers on the grounds of morphology and antigenic structure to be closely related.
\end{abstract}

Nagler (1939) described the effect of $\mathrm{Cl}$. welchii cultures and toxic filtrates on human serum in producing an opalescence and curding (Nagler reaction); later Macfarlane, Oakley \& Anderson (1941) found that egg-yolk saline (a lecithovitellin emulsion) is even more sensitive than human serum (the lecithovitellin (L.v.) reaction). Macfarlane \& Knight (1941) then showed that the production of opalescence in egg-yolk emulsion was due to the action of a lecithinase, which split phosphocholine from lecithin, in the $\mathrm{Cl}$. welchii toxic filtrates which was probably identical with the $\alpha$-toxin. Since then, the Nagler reaction and the lecitho-vitellin (L.v.) reaction have been extensively used for the titration of $\alpha$-toxin of $\mathrm{Cl}$. welchii (Nagler, 1939; van Heyningen, $1941 \mathrm{a}$ ) and for the rapid identification of certain clostridia (Hayward, 1941, 1943).

It is interesting that Nagler (1939) observed a non-pathogenic aerobic sporebearing bacillus which caused an opalescence in human serum like that caused by $\mathrm{Cl}$. welchii; but the effect was not inhibited by $\mathrm{Cl}$. welchii antitoxin. Crook (1942) and Hayward (1943) also mentioned that some aerobic bacteria caused similar opalescence. In the light of these observations we have sought for similar enzymes in the aerobic spore-bearing bacilli. The work started with a survey of the Bacillus group to ascertain which of them produced an eggyolk reaction. A test of 260 identified strains, comprising 24 species, showed that only $\boldsymbol{B}$. cereus, $\boldsymbol{B}$. mycoides and some strains of $\boldsymbol{B}$. anthracis were positive. In comparison with other characteristics generally used for the differentiation of the Bacillus group, the yolk reaction seems to be much more selective. One can hardly find any other characteristics which are confined to only two or three species of this very large group of organisms, and the test deserves the attention of taxonomists of the Bacillus group. We have investigated the 
specificity of the yolk reaction among aerobic spore bearers, the use of the yolk broth and yolk agar for the rapid identification of $\boldsymbol{B}$. cereus and B. mycoides, and the possible correlation between the yolk reaction, haemolysis and phospholipinase activity. The properties of the phospholipinase have been studied in some detail and will be more fully reported in a subsequent paper.

\section{METHODS AND MATERIALS}

Cultures. For this investigation 260 previously identified strains and about 100 freshly isolated strains of the aerobic spore bearers were used. They included 24 species and many classical strains. Most of the cultures were identified according to Gibson \& Topping (1938).

\section{Media}

Egg-yolk saline. Earlier workers used the yolk of one egg in 250 or $500 \mathrm{ml}$. saline. As the sizes of yolks were found to vary, a $5 \%$ (w/v) yolk saline was used instead. It corresponds to one egg-yolk in $300-400 \mathrm{ml}$. saline, as egg-yolks usually" vary from 15 to $20 \mathrm{~g}$. The yolks from fresh eggs were weighed and diluted with physiological saline to the required volume. To every $100 \mathrm{ml}$. of the suspension about $2 \mathrm{~g}$. of kieselguhr were added. After stirring, the mixture was filtered through paper pulp on a Buchner funnel, and then sterilized by passing through a Seitz EK filter. The solution was distributed in small bottles and kept in the refrigerator.

Yolk broth. Yolk broth $(5 \% \mathrm{w} / \mathrm{v})$ was prepared the same way as yolk saline, except that nutrient broth was used instead of saline. It was distributed in tubes and flasks. The medium is perfectly clear by transmitted light and remains stable for weeks if kept sterile in the refrigerator. The yolk-broth tube is most useful for tests of pure cultures. Organisms that produce potent phospholipinase render the medium thickly milky after 8-10 hr. incubation. A thick curd usually appears on the top of the medium in 16-24 $\mathrm{hr}$. Other organisms grow in it without any change of the medium. The difference can be seen in Pl. 1, fig. 1.

Yolk-agar plate. The yolk agar was prepared by mixing equal parts of the above $5 \%$ yolk broth and $4 \%$ nutrient agar at $45^{\circ}$ with sterile precautions and immediately pouring into sterile Petri dishes. The resultant medium is simply an ordinary nutrient agar containing $\mathbf{2 . 5} \%$ egg-yolk. The yolk-agar plate is mainly used for the isolation of phospholipinase-producing organisms, the colonies of which are clearly marked by a thick opaque zone usually extending several $\mathrm{mm}$. from the colony. Pl. 1 , fig. 2 shows how $B$. cereus can be readily isolated from soil by plating on egg-yolk agar. The yolk-agar plate can also be used for testing pure cultures. One plate can be conveniently used for seven cultures. Pl.1, fig. 3 shows the different appearance of the colonies of positive and negative organisms. The width of the opaque zones serves as a rough indication of their relative activities. Negative organisms, instead of producing opalescence, usually render the medium clearer. 


\section{EXPERIMENTAL AND RESULTS}

The specificity of the egg-yolk reaction in aerobic sporing bacilli

Two hundred and sixty identified strains of aerobic sporing bacilli were tested in yolk-broth and yolk-agar plates. The results (Table 1 ) show that the reaction was produced by $\boldsymbol{B}$. cereus, $\boldsymbol{B}$. mycoides and, to a lesser degree, by $\boldsymbol{B}$. anthracis. Especially in $\boldsymbol{B}$. cereus, the ability to react with the egg-yolk was a fairly constant characteristic. Of the 81 strains tested, 73 gave rise to a definite

Table 1. Specificity of the egg-yolk reaction in aerobic sporing bacilli

\begin{tabular}{|c|c|c|c|c|c|c|c|}
\hline & \multirow[b]{3}{*}{$\begin{array}{c}\text { No. of } \\
\text { strains } \\
\text { tested }\end{array}$} & \multicolumn{3}{|c|}{ Yolk-agar test } & \multicolumn{3}{|c|}{ Yolk-broth test } \\
\hline & & \multicolumn{2}{|c|}{ Positive } & \multirow[b]{2}{*}{$\begin{array}{c}\text { Negative } \\
\text { after } \\
5 \text { days }\end{array}$} & \multicolumn{2}{|c|}{ Positive } & \multirow[b]{2}{*}{$\begin{array}{l}\text { Negativ } \\
\text { after } \\
5 \text { days }\end{array}$} \\
\hline & & $\begin{array}{c}\text { In } \\
24 \mathrm{hr} .\end{array}$ & $\operatorname{In}_{1-5 \text { days }}$ & & $\begin{array}{c}\text { In } \\
24 \mathrm{hr}\end{array}$ & $\underset{1-5 \text { days }}{\text { In }}$ & \\
\hline cereus & 80 & 73 & 7 & - & 72 & 5 & 3 \\
\hline B. mycoides & 13 & 4 & $\gamma$ & $\mathbf{2}$ & 11 & - & 2 \\
\hline B. anthracis & 20 & $\mathbf{5}$ & 15 & - & 5 & 12 & 3 \\
\hline
\end{tabular}

Completely negative in both tests

$\begin{array}{lclclc} & \begin{array}{c}\text { No. of } \\ \text { strains } \\ \text { tested }\end{array} & & \begin{array}{c}\text { No. of } \\ \text { strains } \\ \text { tested }\end{array} & & \begin{array}{c}\text { No. of } \\ \text { strains } \\ \text { tested }\end{array} \\ \text { B. megatherium } & 23 & \text { B. brevis } & \mathbf{5} & \text { B. fusiformis } & \mathbf{8} \\ \text { B. circulans } & \mathbf{8} & \text { B. carotarum } & \mathbf{3} & \text { B. alcalophilus } & \mathbf{2} \\ \text { B. subtilis } & \mathbf{3 5} & \text { B. alvei } & \mathbf{3} & \text { B. coagulans } & 4 \\ \text { B. pumilus } & 20 & \text { B. macerans } & 4 & \text { B. repens } & 2 \\ \text { B. licheniformis } & 18 & \text { B. polymyxa } & \mathbf{3} & \text { B. aminovorans } & 1 \\ \text { B. freudenreichii } & \mathbf{1} & \text { B. firmus } & \mathbf{1} & \text { B. orpheus } & 1\end{array}$

opaque zone extending beyond the colony within $24 \mathrm{hr}$.; of the other 8 strains, 7 produced opalescence in the medium immediately underneath the colony after incubation from 1 to 4 days. The N.C.T.C. strain $1599 \mathrm{~W}$, labelled $B$. cereus, failed to show any opalescence in yolk agar, and was finally identified as $B$. subtilis. It was interesting to note that by plating on yolk agar, a strain of $B$. cereus was found to be a mixed culture of a positive $B$. cereus and a negative $\boldsymbol{B}$. licheniformis. Another interesting finding is that the only strain of $B$. megatherium from the National Collection of Type Cultures found positive was identified by other tests as $B$. cereus. The reidentification of these strains has been confirmed by Mrs A. C. Stirling of the East Scotland and Edinburgh College of Agriculture.

Of the 13 strains of $B$. mycoides examined, 11 strains gave the reaction in yolk broth. The yolk-agar plate is not very suitable for $\boldsymbol{B}$. mycoides because the opaque zone is usually obscured by the rapidly spreading growth of the organism, though reaction is evident from the increase of opacity in the medium underneath the centre of the colony. For the readily spreading B. mycoides yolk broth is more satisfactory. 
With $\boldsymbol{B}$. anthracis the reaction was much weaker. With most strains, the opalescence appeared only after $48 \mathrm{hr}$. incubation and seldom extended beyond the colonies. Some correlation between the colony appearance of $\boldsymbol{B}$. anthracis and the yolk reactivity was noted. The strongly reacting strains were usually those with smoother colonies, which were rather like the colony of B. cereus than the typical medusa-head $B$. anthracis colony. Thus the avirulent variant $\mathbf{H}$ and the mucoid variant HM, which Dr P. Bruce White obtained from the

Table 2. Variation of yolk reactivity among strains

\begin{tabular}{|c|c|c|c|c|}
\hline Species & - Strain & $\begin{array}{l}\text { Width of opaque } \\
\text { zone beyond the } \\
\text { colony (mm.) in } \\
\mathbf{2 4} \text { hr. yolk- } \\
\text { agar culture }\end{array}$ & $\begin{array}{c}\text { Time required } \\
\text { to produce } \\
\text { flocculation } \\
\text { in yolk broth } \\
\text { (hr.) }\end{array}$ & $\begin{array}{l}\text { Arbitrary units } \\
\text { of yolk-reacting } \\
\text { substance in culture } \\
\text { supernatant }\end{array}$ \\
\hline \multirow[t]{5}{*}{ B. cereus } & 1081 & 6 & 6 & $2 \cdot 0$ \\
\hline & 945 & 4 & 6 & 1.0 \\
\hline & 5806 & 4 & 8 & 0.35 \\
\hline & 327 & 2 & 30 & Undetectable \\
\hline & 909 & * & 72 & Undetectable \\
\hline \multirow[t]{2}{*}{ B. mycoides } & 684 & * & 8 & 0.42 \\
\hline & 681 & * & 8 & 0.28 \\
\hline \multirow[t]{4}{*}{ B. anthracis } & 'Thorne' & $\mathbf{3}$ & 12 & Undetectable \\
\hline & ' $\mathbf{H M}$ ' & 3 & 12 & Undetectable \\
\hline & 'Vollum' & * & 60 & Undetectable \\
\hline & 'Ellis' & $*$ & 60 & Undetectable \\
\hline
\end{tabular}

*= The opaque zone confined to the area underneath the colony.

typical strain 'Vollum', are much more potent in yolk reaction than their parent strain. Also, the smooth and smooth-mucoid variants that we obtained from a virulent strain Ellis by prolonged cultivation in broth, were found to be more active than the original strain. Furthermore, the two 'Pasteur vaccine' variants obtained from the National Collection of Type Cultures were also more active.

The substance reacting with egg-yolk could be demonstrated in the culture filtrate of most strains of $B$. cereus and $B$. mycoides, but not in any of the strains of $\boldsymbol{B}$. anthracis. Like other biochemical activities, the yolk-reacting activity of these organisms also varies among strains (Table 2).

\section{The mechanism of the yolk reaction}

As with the $\alpha$-toxin of $C l$. welchii (Macfarlane \& Knight, 1941), the yolk reaction of $\boldsymbol{B}$. cereus and $\boldsymbol{B}$. mycoides also was found to be due to the action of a phospholipinase. The yolk reactivity, measured by a modified van Heyningen's turbidimetric method (1941 $a)$ ran in parallel with the phospholipinase activity, measured by the Macfarlane \& Knight's method (1941). Differing from the lecithinase of $\mathrm{Cl}$. welchii, the phospholipinase of $\boldsymbol{B}$. cereus attacks both lecithin and kephalin, with the production of acid-soluble organic $\mathbf{P}$ but no inorganic $\mathbf{P}$. The hydrolytic products of lecithin have been isolated and 
identified as neutral fat and phosphocholine. The properties of the enzyme, or enzymes, have been studied in some detail and will be reported more fully in a subsequent paper.

\section{The association of yolk reaction with haemolytic activity}

In $\mathrm{Cl}$. welchii, the lecithinase activity, the yolk-reaction activity and the haemolytic activity were found to be closely associated. This association was also noted in $\boldsymbol{B}$. cereus and $\boldsymbol{B}$. mycoides. Strains producing the yolk reaction were always haemolytic. The opaque zone and the haemolytic zone produced in yolk agar and blood agar by 7 strains of $B$. cereus are compared in Pl. 1 , fig. 4. The yolk-reaction activity and the haemolytic activity of the culture filtrates of a number of strains of $\boldsymbol{B}$. cereus and $\boldsymbol{B}$. mycoides also have been determined by the colorimetric methods of van Heyningen (1941 $a, b)$ and Herbert (1941). For most strains these two activities ran in c̈lose parallel. But a few strains had a much higher ratio of haemolytic activity. Thus the culture filtrate of strain 720, which showed only trace of yolk reactivity, was fairly haemolytic. The possibility of a second haemolysin, unrelated to the yolkreacting substance, is under investigation. Although there is no direct evidence to show that haemolysis is due to the phospholipinase activity, indirect evidence strongly suggests that part, if not all, of the haemolysin of $B$. cereus and $B$. mycoides is closely correlated with the yolk-reacting substance or phospholipinase. An interesting observation is that both haemolysis and the hydrolysis of lecithin by culture filtrates of $B$. cereus are inhibited by normal serum (human, horse, ox, sheep, rabbit) in very high dilution.

$B$. anthracis generally is regarded as non-haemolytic, and lack of haemolysis has long been used as an important criterion for differentiating it from the saprophytic spore-bearing bacilli. However, it was observed that with most strains of $\boldsymbol{B}$. anthracis examined, zones of haemolysis limited to the area underneath each colony developed after incubation for 2-3 days on sheep-blood agar. Thus haemolytic activity seems to be associated with the yolk-reaction activity, inasmuch as the opalescence produced by $B$. anthracis on yolk-agar plate also developed very slowly and seldom extended beyond the colony. It must be pointed out that although haemolysis and yolk reaction can be demonstrated in blood-agar and yolk-agar plates, neither haemolysin nor the yolk-reacting substance has ever been detected in the culture filtrate of even the most active strain of $B$. anthracis yet examined. The sheep erythrocytes used in the blood agar were washed because it was found that haemolysis produced by these organisms was strongly inhibited by normal serum. There is considerable variation in the sensitivity of erythrocytes from different species of animals.

\section{DISCUSSION}

The group of aerobic sporing bacilli comprises a very large number of species, the differentiation of which is still a problem for taxonomists. Although several classifications have been put forward by various workers (Bergey, Breed, Murray \& Hitchens, 1939; Gibson \& Topping, 1938; Smith \& Clark, 1937; 
Lamanna, $1940 a, b \& c$ ), there is still much confusion and new tests would seem to be necessary for a satisfactory classification. With the simple egg-yolk reaction we have been able to pick out from this large group of organisms three species which have been suspected by previous workers to be closely related. $\boldsymbol{B}$. mycoides is usually distinguished from other aerobic sporing bacilli solely by its characteristic filamentous colony. Apart from this feature, which is very liable to variation (Lewis, 1932; Gordon, 1940; Lamanna, 1940 b), B. mycoides is almost indistinguishable from $B$. cereus. Their close relationship is further suggested by the finding of Lamanna (1940 b) that many strains of $B$. mycoides possess the same spore antigen as that of $B$. cereus. Our finding that so far these are the only species in the large group of aerobic sporing bacilli found to produce this phospholipinase enzyme, strongly supports the view that they are related. The fact that $B$. anthracis can cause a rather weak and siow yolk reaction is also of interest. Although typical $\boldsymbol{B}$. anthracis is quite distinct from $\boldsymbol{B}$. cereus and $B$. mycoides, these latter are the organisms most likely to be confused with the anthrax bacillus; thus the strains of so-called ' $B$. anthracoides', extensively studied by Grierson (1928), were mostly $B$. cereus. The results of our numerous biochemical tests support the opinions based on morphological and physiological studies of other workers, viz. that $B$. cereus and $B$. mycoides are closely related to $B$. anthracis.

The egg-yolk reaction has two advantages over other tests generally used for the identification of the aerobic sporing bacilli. First, as it is much more selective, shown only by three closely related species, a positive yolk reaction will exclude many species otherwise similar. Secondly, the characteristic opaque zone around the colony enables a rapid Pecognition of $\boldsymbol{B}$. cereus in a mixed culture. Confirmation of the usefulness of the test in the taxonomy of the Bacillus group depends on its application by many other workers to a greater number of strains.

Finally, as $B$. cereus and $B$. mycoides are among the most common laboratory contaminants, it would seem to be worth while to take precautions against contamination in the titration of certain toxins using the egg-yolk reaction, expecially when the reaction mixtures are incubated overnight.

We wish to express our thanks to Dr St John Brooks, formerly Curator of the National Collection of Type Cultures for his kindness in providing us with a large number of strains of aerobic sporing bacilli, also to Dr T. Gibson and Mrs A. C. Stirling, East of Scotland and Edinburgh College of Agriculture, for many standard strains of $B$. cereus and other species.

\section{REFERENCES}

Bergey, D. H., Breed; R. S., Murray, E. G. D. \& Hitchens, A. P. (1939). Manual of Determinative Bacteriology, 5th ed. Baltimore: Williams and Wilkins Co.

Crook, E. M. (1942). The Nagler reaction: the breakdown of lipoprotein complexes by bacterial toxins. Brit. J. exp. Path. 23, 37.

Grbson, T. \& Topping, L. E. (1938). Further study of aerobic spore-forming bacilli. Proc. Soc. Agric. Bact. p. 43.

Gordon, R. E. (1940). Dissociation and bacteriophagy of Bacillus mycoides and Bacillus cereus. J. Bact. 39, 98. 
Grierson, A. M. M. (1928). 'Bacillus anthracoides.' A study of its biological characters and relationships and its pathogenic properties under experimental conditions. J. Hyg., Camb., 27, 306.

HAYWARD, N. J. (1941). Rapid identification of $\mathrm{Cl}$. welchii by the Nagler reaction. Brit. med. J. 1, 811.

HAYWARD, N. J. (1943). The rapid identification of $C l$. welchii by Nagler tests in plate cultures. J. Path. Bact. 55, 285.

Herbert, D. (1941). A simple colorimetric method for the estimation of haemolysis and its application to the study of streptolysin. Biochem. J. 35, 1116.

Heyningen, W. E. van (1941 a). Estimation of the $\alpha$-toxin of $\mathrm{Cl}$. relchii, type A. Biochem. J. 35, 1246.

Heyningen, W. E. van (1941 b). Partial purification of the toxins of $\mathrm{Cl}$. welchii, type A. Separation of $\alpha$ and $\theta$ toxins. Biochem. J. 35, $125 \%$.

Lamanna, C. $(1940 a)$. The taxonomy of the genus Bacillus. Modes of spore germination. J. Bact. 40, 347.

Lamanna, C. (1940b). Taxonomy of genus Bacillus: differentiation of small-celled species by means of spore antigens. J. infect. Dis. 67, 193.

Lamanna, C. $(1940 c)$. Taxonomy of genus Bacillus: differentiation of large-celled species by means of spore antigens. J. infect. Dis. 67, 205.

Lewis, I. M. (1932). Dissociation and life cycle of Bacillus mycoides. J. Bact. 24, 381.

Macfarlane, M. G. \& KNight, B. C. J. G. (1941). The biochemistry of bacterial toxins. 1. The lecithinase activity of $\mathrm{Cl}$. welchii toxins. Biochem. J. 35, 884.

Macfarlane, R. G., Oakrey, C. L. \& Anderson, C. G. (1941). Haemolysis and the production of opalescence in serum and lecitho-vitellin by the $\alpha$-toxin of Cl. welchii. J. Path. Bact. 52, 99.

Nagler, F. P. O. (1939). Observations on a reaction between the lethal toxin of Cl. reelchii (type A) and human serum. Brit. J. exp. Path. 20, 473.

Smith, N. R. \& Clark, F. F (1937). A proposed grouping of the mesophilic aerobic spore-forming bacilli. Proc. Soil Sci. Soc. Amer. $2,255$.

\section{EXPLANATION OF PLATE}

Fig. 1. The yolk-broth reaction, after $24 \mathrm{hr}$. incubation: (1) $B$. cereus, active strain; (2) B. mycoides; (3) B. cereus, rather weak strain; (4) B. anthracis; (5) B. subtilis; (6) B. megatherium; (7) B. licheniformis; (8) uninoculated yolk broth.

Fig. 2. The isolation of $B$. cereus from soil by egg-yolk agar plate; note the four colonies with opaque zone.

Fig. 3. The egg-yolkagar plate test: (1) B. cereus, active strain; (2) B. mycoides; (3) B. anthracis;

(4) B. megatherium; (5) B. cereus, rather weak strain; (6) B. licheniformis; (7) B. subtilis;

(8) B. anthracis, strain 'vollum'; (9) B. anthracis ' $H$ ' variant of strain 'vollum';

(10) B. anthracis 'HM' variant of strain 'vollum'.

Fig. 4. Seven strains of $B$. cereus grown on yolk-agar plate (left) and blood-agar plate (right); note the correlation between yolk flocculating activity and haemolytic activity. 
Journal of General Microbiology, Vol. 2, No. 3
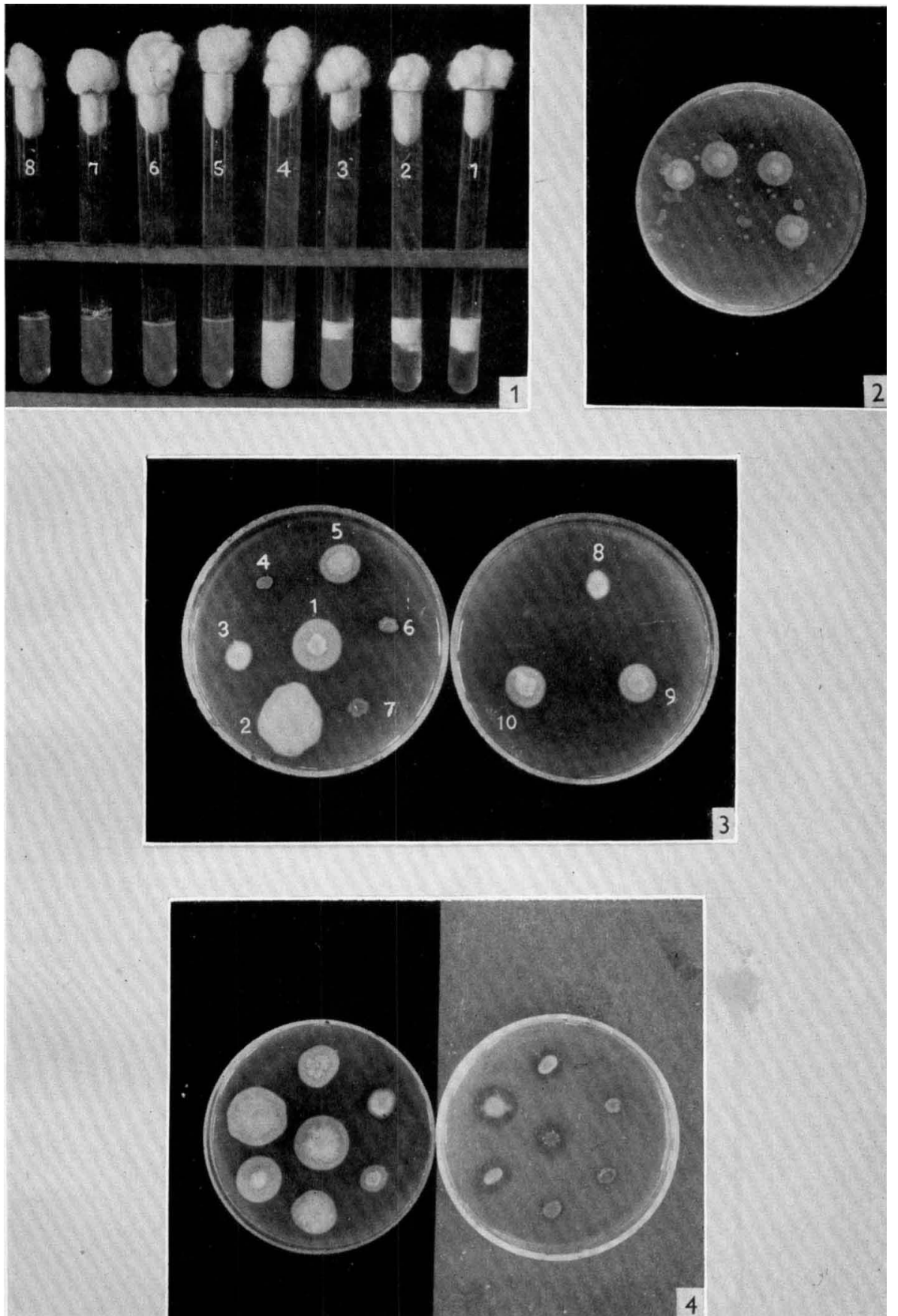

Figs. 1-4

C. A. McGaughey and H. P. Ciru-'The egg-yolk reaction of aerobic sporing Bacilli. Plate: 1 